Article

\title{
Bidding of Energy Sources and Energy Storage System in Day-ahead Markets
}

\author{
Mustafa Al-Swaiti ${ }^{1}$, and Ali Al-Awami ${ }^{2, *}$ \\ 1 mustafasweiti@gmail.com \\ 2 aliawami@kfupm.edu.sa \\ * Correspondence: aliawami@kfupm.edu.sa; Tel.: +966-54-933-1381
}

\begin{abstract}
In this work, the Pumped Storage Unit (PSU) is proposed to be integrated with wind-thermal generation system owned by a company whose aim is to maximize its profit through optimal self-scheduling of its units by finding the best bidding strategy in day-ahead energy market. The mathematical formulation of the scenario based unitcommitment and coordinated trading problem is formulated as a stochastic mixed integer linear program. The formulation takes into account several uncertain parameters; such as the wind power generation, energy market prices, and imbalances up/down prices. The expected total profit obtained from energy trading with and without coordinating pumped storage system (PSS) with thermal-wind generation system were compared, and a significant improvement in profit resulted from coordination was observed. Furthermore, coordination between PSS and wind-thermal generation improve the conditional value at risk $(\mathrm{CVaR})$ which monitors the biding risk level.
\end{abstract}

Keywords: pumped storage system; coordinated PSS with wind-thermal generation; uncoordinated PSS; risk; mixed integer programming; thermal unit commitment schedule; PSS modes schedule

\section{NOMENCLATURE}

The notations that used through the paper are stated bellow:

A. Indices:

$\begin{array}{ll}t & \text { Bidding period. } \\ s & \text { Scenario. } \\ g & \text { Thermal unit. } \\ n & \text { PSS unit. } \\ d & \text { Wind plant. } \\ e & \text { SegmentB. }\end{array}$

B.Decision variables:

$\begin{array}{ll}P p & \text { Optimal bid of thermal unit. } \\ P w & \text { Optimal bid of wind unit. } \\ P H & \text { Optimal bid of PSS plant. } \\ \text { Pacm } & \begin{array}{l}\text { Actual power output from } \\ \text { thermal to the market. }\end{array} \\ \text { Pacp } & \begin{array}{l}\text { Actual power output from } \\ \text { thermal to PSS. }\end{array}\end{array}$

"This work was supported in part by the Research Institute of King Fahd university of Petroleum \& Minerals". M. S. Sweiti and A. T. Al-Awami are with King Fahd university of Petroleum \& Minerals Dhahran, Saudi Arabia (e-mail: (g201104130,aliawami)@kfupm.edu.sa) 


\begin{tabular}{|c|c|}
\hline Wacm & $\begin{array}{l}\text { Actual power output from wind } \\
\text { plant to the market. }\end{array}$ \\
\hline$W^{a c p}$ & $\begin{array}{l}\text { Actual power output from wind } \\
\text { plant to PSS. }\end{array}$ \\
\hline$H^{a c}$ & $\begin{array}{l}\text { Actual power output from PSS } \\
\text { unit. }\end{array}$ \\
\hline$u$ & $\begin{array}{l}\text { Thermal unit state; } 1 \text { means } \mathrm{ON} ; 0 \\
\text { means OFF. }\end{array}$ \\
\hline$P$ & $\begin{array}{l}\text { PSS unit state; } 1 \text { means the unit in } \\
\text { pumping mode; } 0 \text { means Not. }\end{array}$ \\
\hline G & $\begin{array}{l}\text { PSS unit state; } 1 \text { means the unit in } \\
\text { generation mode; } 0 \text { means Not. }\end{array}$ \\
\hline$\delta$ & $\begin{array}{l}\text { Thermal power output } \\
\text { corresponding to a segment of } \\
\text { piecewise linear thermal heat rate } \\
\text { curve. }\end{array}$ \\
\hline$\zeta$ and $\eta$ & $\begin{array}{l}\text { Auxiliary variables for computing } \\
\text { CVaR }\end{array}$ \\
\hline MarkPump & $\begin{array}{l}\text { Optimal offer from PSS to } \\
\text { purchase energy from them } \\
\text { market. }\end{array}$ \\
\hline Pump & $\begin{array}{l}\text { Total pumped energy through } \\
\text { PSS. }\end{array}$ \\
\hline$V$ & $\begin{array}{l}\text { Energy level in the upper } \\
\text { reservoir }\end{array}$ \\
\hline$\rho$ & Spot market energy price. \\
\hline$\rho^{u}, \rho^{o}$ & $\begin{array}{l}\text { Under- and over-generation } \\
\text { imbalance penalties as multipliers } \\
\text { of the energy price. }\end{array}$ \\
\hline
\end{tabular}

C. Stochastic variables:
$W^{a c}$
Actual wind power output.
$\rho \quad$ Spot market energy price.
$\rho^{u}, \rho^{o} \quad$ Under- and over-gener
multipliers of the energy price.

D. Other variables:

PROFETS Total expected profits. 


\begin{tabular}{|c|c|}
\hline$C V a R \alpha$ & $\begin{array}{l}\text { Conditional value at risk at } \\
\text { the } \alpha \text { confidence interval. }\end{array}$ \\
\hline$\alpha$ & Confidence level. \\
\hline$\beta$ & Risk-aversion parameter. \\
\hline PFT & $\begin{array}{l}\text { Thermal profits associated with } \\
\text { a scenario. }\end{array}$ \\
\hline PFW & $\begin{array}{l}\text { Wind profits associated with a } \\
\text { scenario. }\end{array}$ \\
\hline PFPSS & $\begin{array}{l}\text { PSS profits associated with a } \\
\text { scenario. }\end{array}$ \\
\hline PFIMB & $\begin{array}{l}\text { Imbalances profits associated } \\
\text { with a scenario. }\end{array}$ \\
\hline $\operatorname{ImbUp}$ & $\begin{array}{l}\text { Imbalance-up, or total over- } \\
\text { generated energy in excess of } \\
\text { combined schedule. }\end{array}$ \\
\hline $\operatorname{ImbDn}$ & $\begin{array}{l}\text { Imbalance-down, or total under- } \\
\text { generated energy in deficit of } \\
\text { combined schedule. }\end{array}$ \\
\hline
\end{tabular}

E. Parameters and constraints:

\begin{tabular}{|c|c|}
\hline StUpCost & Start-up cost of a thermal unit. \\
\hline MinUp & $\begin{array}{l}\text { Minimum up-time of a thermal } \\
\text { unit. }\end{array}$ \\
\hline $\operatorname{MinDn}$ & $\begin{array}{l}\text { Minimum down-time of a thermal } \\
\text { unit. }\end{array}$ \\
\hline InitUp & $\begin{array}{l}\text { Initial minimum up-time of a } \\
\text { thermal unit. }\end{array}$ \\
\hline InitDn & $\begin{array}{l}\text { Initial minimum down-time of a } \\
\text { thermal unit. }\end{array}$ \\
\hline$R U$ & $\begin{array}{l}\text { Thermal ramp-up rate [megawatt } \\
\text { per hour }(\mathrm{MW} / \mathrm{h}) \text { ]. }\end{array}$ \\
\hline$R D$ & $\begin{array}{l}\text { Thermal ramp-down rate } \\
(\mathrm{MW} / \mathrm{h}) \text {. }\end{array}$ \\
\hline FC & Thermal fuel cost. \\
\hline$a, b, c, d$ & $\begin{array}{l}\text { Thermal heat rate curve } \\
\text { parameters. }\end{array}$ \\
\hline$A A$ & $\begin{array}{l}\text { Offset of a piecewise linear } \\
\text { thermal heat rate curve. }\end{array}$ \\
\hline Slope & $\begin{array}{l}\text { Slope of a segment of the } \\
\text { piecewise linear thermal heat rate } \\
\text { curve. }\end{array}$ \\
\hline BrkPt & $\begin{array}{l}\text { Break point of a segment of the } \\
\text { piecewise linear thermal heat rate } \\
\text { curve. }\end{array}$ \\
\hline$u_{\text {IC }}$ & Initial state of a thermal units. \\
\hline
\end{tabular}




\begin{tabular}{|c|c|}
\hline$\underline{P}, \bar{P}$ & $\begin{array}{l}\text { Minimum and maximum thermal } \\
\text { power output. }\end{array}$ \\
\hline Wmax & Rated wind power output. \\
\hline $\mathrm{CHO}$ & Operation cost for PSS unit. \\
\hline$V_{-}$initial & $\begin{array}{l}\text { Initial energy level in the upper } \\
\text { reservoir. }\end{array}$ \\
\hline$V_{\text {final }}$ & $\begin{array}{l}\text { final energy level in the upper } \\
\text { reservoir. }\end{array}$ \\
\hline$\mu p$ & Pumping efficiency. \\
\hline$\mu g$ & Pumping efficiency. \\
\hline$V \min , V \max$ & $\begin{array}{l}\text { minimum and maximum energy } \\
\text { level in the upper reservoir. }\end{array}$ \\
\hline PPSH & Rated PSS unit power output. \\
\hline$N T$ & Number of periods. \\
\hline Ns & Number of scenarios. \\
\hline $\mathrm{Ng}$ & Number of thermal units. \\
\hline $\mathrm{Nd}$ & Number of wind plants. \\
\hline $\mathrm{Nu}$ & Number of PSS unit. \\
\hline$N E$ & Number of segments. \\
\hline$\pi$ & Probability of a scenario. \\
\hline
\end{tabular}

\section{INTRODUCTION}

Recently,electricity demand has been increasing rapidly. Furthermore, several forecasting studies expect a decrease in fossil fuel recourses in the coming years. Because of that, the cost of this depleted energy resource is increasing. Also, fossil-fueled power plants produce gases that adversely affect the environment. Therefore, interest has increased drastically in renewable energy resources as a means to meet energy challenges in a sustainable ways $[1,2]$.

Wind and solar energy are some of the main resources of renewable energy. A major challenge for integrating the renewable energy resources their variability and limited controllability [3-5]. This can affect negatively the reliability, security, economic efficiency and stability of the power system [6, 7]. Storage systems are proposed mitigate these negative impacts and reduce the operational cost of power generation [6-8]. For large systems with large penetration of uncertain renewable energy, the use of bulk energy storage like pumped storage system (PSS) is recommended [810], the idea behind the use of PSS is that during off-peak generating hours when the generation cost is low, water is pumped to the upper reservoir. This is reutilized via hydro-turbines during peak load hours, when generation cost is high.

In pool-based energy markets, the market price in each hour is determined based on bids/offers by supplies demands $[5,9,10]$. The winning participants receive/pay the market clearing price, which is determined by the intersection between the demand and the supply curves in each hours. However, actual real time generation may deviate from the scheduled quantity. This is especially true when the generation company has uncertain generation like wind turbines. In addition, there are always changes from the demand side. These changes should be demolished to maintain the system security. Because of that, real time or spot prices are cleared in the real time hour by hour, as a generation company will pay/receive the spot price for its under-generated quantities [5, 10, 11].

The presences of PSS can reduce the uncertainty level by decreasing or increasing the pumped or generated power during the pumping and generation modes. Figure 1 illustrates clearly the operation of PSS. 


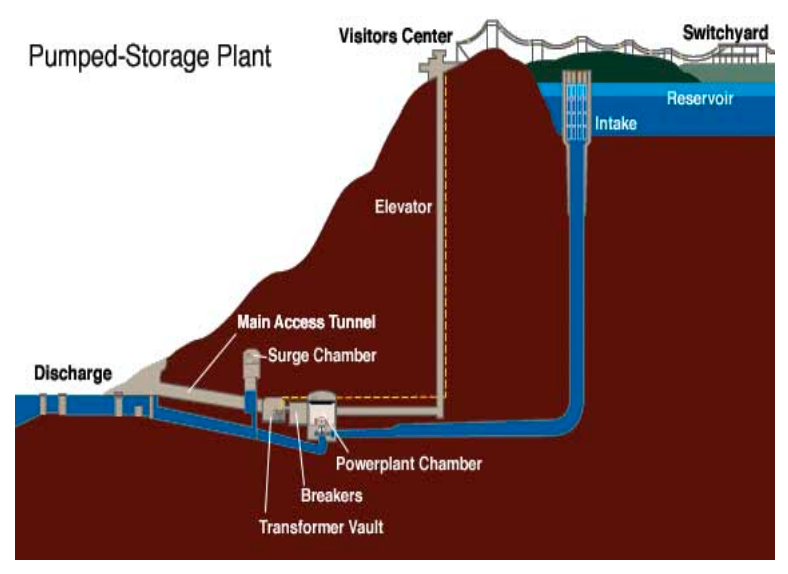

Fig.1 Pumped storage plant configuration[12].

Several works have been reported regarding the application of PSS in power system operation in $[7,13,14]$ different techniques have been presented to determine the optimal installed capacity of the upper reservoir and the optimal capacity of the hydro units for PSS. In [13] the uncertainties in load and renewable generation forecasts have been taken into account by developing scenarios. The conventional generations oblige technical constraints to accept wind power generation. There is many megawatts of wind generation will be refused because of these constraints [7, 15]. To increase the power sharing from the wind farm that already exist and also allow more penetration of wind power, hybrid system consisting of wind and hydro power stations (HPSs) have been proposed. The results show for including HPSs into the proposed systems make extraordinarily increasing in the wind penetration also it increase the system capacity to avoid using the expensive units in the peak generation periods [15].

In [16], a robust unit commitment schedule had been done for thermal units under the worst case scenario of the wind generation. The main objective is to insure more reliability to the system by minimizing the total generation costs under this condition and study the effect of including pumped storage units on the total cost. The fluctuation behavior of wind generation is considered by developing scenarios depending on the historical wind date. The unit commitment schedule depends on these scenarios; so the quality of the unit commitment schedule will increase as much as the number of scenarios increased. The worst case scenario had been forecasted in each time horizon in the day and the unit commitment schedule had been obtained based on it. The formulation had been built to insure high utilization of wind power and to minimize the total cost under the worst case scenario. The determination the quality of the selection solution can be obtained by employing an integer variable which represents the uncertainty level in the wind generation. The adjustment of this variable controls the system robustness and the percentage sharing of the wind power. After that, minimizing the cost of the maximum utilized wind power can be obtained at any selection of this integer variable. The same methodology had been used to obtain the solution of the unit commitment with including the PSS. The result showed that PSS stores and generates more power when the uncertainty level increased in order to maintain the system robustness. In this work, the wind output power is represented stochastically, but the prices of imbalances are not included. The main objective here is to insure the system robustness not to maximize the owner profit by considering a pool based electricity market.

In [5], PSS is proposed to manage the energy imbalances for a generation company that owns wind generation. The goal is to optimize day-ahead energy market bidding. In this work, the optimization problem is formulated as twostage stochastic programming problem with two random parameters, wind generation and energy prices. The optimal bid for a day-ahead in the electricity spot market should be determined on spot, however; the optimal output from the generation facilities will be determined by the resources variables. In order to reduce the penalties that could be caused by energy deviations an isolated pumped-storage plant is used. In this work the objective is to maximize the generation company's profit.

To avoid paying penalties when the system has a large scale of wind penetration using fast thermal units could be a good solution. However, these units have a limited generation capacities also are usually have high operation costs, 
for long term operation having PSS will be more efficient over these small thermal units, PSS operate at low operation cost with very high ramp response [17-20].

In this work PSS is proposed to be a good solution to decrease the uncertainties and the risk bidding it will also increase the generation company's profits which is assumed to be an independent power producer owning wind farm, thermal units and PSS, Conditional Value at Risk (CVaR) have been used to measure the bidding risk level. The optimization problem is modeled as a stochastic program (SP). The stochastic parameters considered are energy market clearing price, wind output generation, and the imbalance prices. The results show that the coordinated PSS has advantages over the uncoordinated one by decreasing the risk and increasing the total profits. Also the results show the additional value of having PSS in both cases.

The scenarios for day-ahead hourly wind power outputs are generated using wind forecast and statistical properties for wind ramping rate. Using expected value and standard deviation for any given hour, Ns scenarios are generated. These wind power output generated in that manner might violates the ramping rate constrains, as these constrains are disregarded. Therefore, the values of wind power output must be modified to comply with ramping rate constrains, in order to correctly couple each two consecutive hours. To accomplish that task, a number of random values for wind power output in each value for every scenario are produced by adding a random ramping rate considering the mean value and the standard deviation to preceding value. The criteria for choosing one value from the set of random values are the minimum distance between the new value and the originally generated values. The procedures for scenario generation is detailed in the following steps:

1. Use the expected value and standard deviation for each given hour to generate Ns scenarios for each hour in the day-ahead separately $\mathrm{W}_{\mathrm{t}, \mathrm{Ns}}^{\mathrm{ac}}$.

2. Generate random ramping rate using standard deviation and mean for each hour.

3. Add the generated value in (2) to $\mathrm{W}_{\mathrm{t}, \mathrm{s}}^{\mathrm{ac}}$, this is the first value in the first hour in first scenario which is generated in (1), the obtained value here is $\mathrm{W}_{\mathrm{t}+1, \mathrm{~s}^{\prime}}^{\mathrm{ac}}$. Repeat this for all scenarios.

4. Compare the obtained value in $\mathrm{W}_{\mathrm{t}+1, \mathrm{~s}}^{\mathrm{ac}}$, with all values in all scenarios $\mathrm{W}_{\mathrm{t}+1, \mathrm{~s}}^{\mathrm{ac}}$ and select the closest one.

5. Swap the selected value in (4) to be associated withW $W_{t, s}^{\mathrm{ac}}$.

6. In the same way do the previous steps for all scenarios in hour 1.

7. Do the steps from (1) to (6) for all hours.

To generate scenarios for day-ahead energy market prices and imbalances prices ARIMA models [9, 21]are commonly used. The participants receive market clearing price for their winning bids. Nevertheless, real-time actual generation may deviate from the scheduled quantity. In some markets such as the Iberian market, the penalties for over generation are different from under generation. For over generation, the generation company gets at most the market clearing price at that hour. For under-generation it pays at least the market clearing price [9, 22].

In previously mentioned scenario generation process, a huge number of scenarios are obtained for each uncertain parameter. This makes the optimization problem overloaded with data and scenario tree intractable. Therefore, the number of scenarios needs to be reduced to have reasonable number of scenarios. The algorithm used for reducing the number of scenarios is the forward selection algorithm $[9,23]$, the algorithm is executed in the following steps:

1. Start with empty subset $\omega$ whose first member has minimum sum of distances from members of original set $\Omega$

2. The second member in $\omega$ is chosen such that the sum of distances of members of $\omega$ from members of $\Omega-\omega$ is minimized

3. The procedures are continued until the desired number of scenarios is obtained. 


\section{PROBEM FORMULATION}

\section{A.Objective Function:}

Maximize $\quad$ PPROFITS $\left.+\beta^{*} \mathrm{CVaR} \alpha\right]$

Where

$[$ PROFITS $]=\sum_{s=1}^{\mathrm{Ns}} \Pi_{\mathrm{s}} *\left[\begin{array}{c}\mathrm{PFT}_{\mathrm{s}}+\mathrm{PFW}_{\mathrm{s}}+\mathrm{PFPSS}_{\mathrm{s}} \\ +\mathrm{PFIMB}_{\mathrm{s}}\end{array}\right]$

The first term in (1) represents the expected profits of the generating company. As shown in (2), the profits term consists of four components. Equations (3)-(6) shows each of these components.

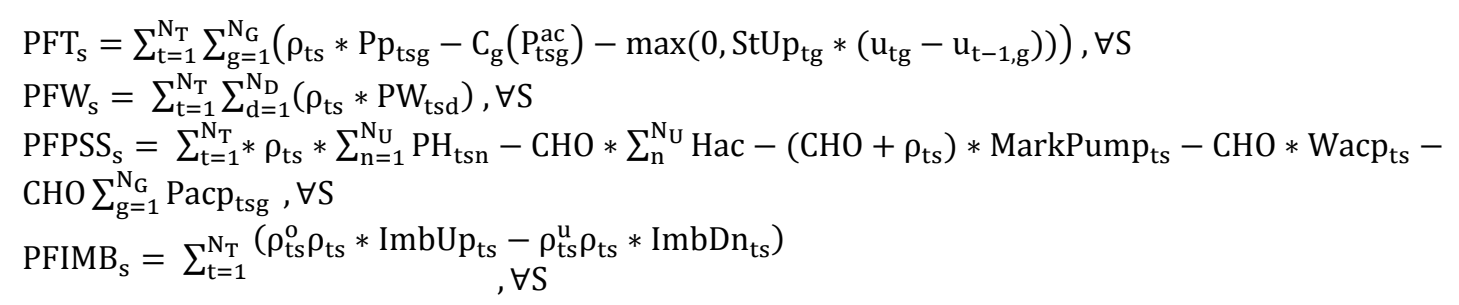

Equation (3) contains the scenario profits from thermal units; taking into account the thermal operation cost per unit and the start-up costs per generation units per period. Equation (4) express the wind profits per scenario, this profit is a function of the energy prices and the bidding energy corresponds with wind, in this term the operation and maintenance costs are assumed to be neglected. Equation (5) describes PSS scenario profits, it contains the revenue from PSS bidding energy; the unit operation cost of the PSS has been considered while unit is operate in the pumping mode or in the generation mode. Equation (6) presents the imbalance up profits and the imbalance down penalty per scenario; the imbalance up or down caused by the mismatch between the actual and scheduled generation. One of these two terms can have a non-zero value because the up and down generation can't occur at the same hour. The mathematical explanations for up/down imbalances is expressed intensively in [9].

The second term in (1) represent a risk metric at a confidant level $\alpha . \beta$ is a weighting factor that represents the riskaversion attitude.

\section{B. The Constraints:}

\section{Risk Analysis Constraints:}

For risk analysis constraints (7) - (9) are needed, more comprehensive explanation about CVaR can be found in [1, $9,24,25]$.

$-[\text { PROFETS }]_{S}+\zeta-\eta_{s} \leq 0, \forall S$

$\eta_{\mathrm{s}} \geq 0, \forall S$

CVaRa $=\zeta-\frac{1}{1-\alpha} \sum_{s}^{N_{s}} \prod_{s} * \eta_{s}$

\section{Imbalances Modeling:}

Constraints (10) - (12) are employed to model the imbalances. Note that imbalances refer to the difference between the total bidding and actual power generation from wind, thermal and PSS. It is called imbalance down if this difference is positive, and vice versa. Constraint (11) sets the maximum value of the imbalance up. This case is reached when the total bids equal to zero but in real time there is a generation output. Constraint (12) sets the limits of 
imbalance down. The maximum limit can be reached if the total bids equal the maximum capacity of the generator resources but the actual generation in real time equal to zero.

$$
\begin{aligned}
& \operatorname{ImbDn}_{\mathrm{ts}}-\operatorname{ImbUp}_{\mathrm{ts}}=\sum_{\mathrm{n}=1}^{\mathrm{N}_{\mathrm{U}}} \mathrm{PH}_{\mathrm{tsn}}+\sum_{\mathrm{d}=1}^{\mathrm{N}_{\mathrm{D}}} \mathrm{PW}_{\mathrm{tsd}}+\sum_{\mathrm{g}=1}^{\mathrm{N}_{\mathrm{G}}} \mathrm{Pp} \mathrm{ptsg}_{\mathrm{tsg}}-\sum_{\mathrm{d}=1}^{\mathrm{N}_{\mathrm{D}}} \mathrm{W}_{\mathrm{tsd}}^{\mathrm{acm}}-\sum_{\mathrm{g}=1}^{\mathrm{N}_{\mathrm{G}}} \mathrm{P}_{\mathrm{tsg}}^{\mathrm{acm}}-\sum_{\mathrm{n}=1}^{\mathrm{N}_{\mathrm{U}}} \mathrm{H}_{\mathrm{tsn}}^{\mathrm{ac}}, \forall \mathrm{t}, \mathrm{s} \\
& 0 \leq \operatorname{ImbUp}_{\mathrm{ts}} \leq \sum_{\mathrm{d}=1}^{\mathrm{N}_{\mathrm{D}}} \mathrm{W}_{\mathrm{tsd}}^{\mathrm{ac}}+\sum_{\mathrm{g}=1}^{\mathrm{N}_{\mathrm{G}}} \mathrm{P}_{\mathrm{tsg}}^{\mathrm{ac}}+\sum_{n=1}^{N_{u}} \mathrm{H}_{\mathrm{tsn}}^{\mathrm{ac}}, \forall \mathrm{t}, \mathrm{s} \\
& 0 \leq \operatorname{ImbDn}_{\mathrm{ts}} \leq \sum_{\mathrm{d}=1}^{\mathrm{N}_{\mathrm{D}}} \overline{\mathrm{W}_{\mathrm{d}}}+\sum_{\mathrm{g}=1}^{\mathrm{N}_{\mathrm{G}}} \mathrm{u}_{\mathrm{tg}} * \overline{\mathrm{P}_{\mathrm{g}}}+\sum_{\mathrm{n}=1}^{\mathrm{N}_{\mathrm{U}}} \mathrm{G}_{\mathrm{tsn}} * \mathrm{PPSH}, \forall \mathrm{t}, \mathrm{s}
\end{aligned}
$$

\section{Wind Operation Constraints:}

The actual wind generation is forecasted in each scenario in each hour of the day. Some of this power can be stored via PSS facilities and the rest can be delivered to the market. Equation (13) is installed to address this fact. Constraint (14) is employed to insure that the bidding energy from wind is within the wind plant capacity.

$\mathrm{W}_{\mathrm{tsd}}^{\mathrm{ac}}=\mathrm{W}_{\mathrm{tsd}}^{\mathrm{acp}}+\mathrm{W}_{\mathrm{tsd}}^{\mathrm{acm}}, \forall \mathrm{t}, \mathrm{s}, \mathrm{d}$

$0 \leq \mathrm{PW}_{\mathrm{tsd}} \leq \overline{\mathrm{W}_{\mathrm{d}}}, \forall \mathrm{t}, \mathrm{s}, \mathrm{d}$

\section{Thermal Operation Constraints:}

Relation (15) demonstrates the fact that the total actual thermal generation can be either delivered to the market or stored in the PSS reservoir. Ramping rate constraints are given in (16). Relations (17) and (18) are employed to insure the bidding and actual power variables from the committed thermal units are within the unit's thermal constraints.

$$
\begin{aligned}
& \mathrm{P}_{\mathrm{tsg}}^{\mathrm{ac}}=\mathrm{P}_{\mathrm{tsg}}^{\mathrm{acp}}+\mathrm{P}_{\mathrm{tsg}}^{\mathrm{acm}}, \forall \mathrm{t}, \mathrm{s}, \mathrm{g} \\
& -\mathrm{RD}_{\mathrm{g}} \leq \mathrm{P}_{\mathrm{tsg}}^{\mathrm{ac}}-\mathrm{P}_{\mathrm{t}-1, \mathrm{~s}, \mathrm{~g}}^{\mathrm{ac}} \leq \mathrm{RU}_{\mathrm{g}}, \forall \mathrm{t}, \mathrm{s}, \mathrm{g} \\
& \mathrm{u}_{\mathrm{tg}} * \underline{\mathrm{P}_{\mathrm{g}}} \leq \mathrm{Pp}_{\mathrm{tsg}} \leq \mathrm{u}_{\mathrm{tg}} * \overline{\mathrm{P}_{\mathrm{g}}} \\
& \mathrm{u}_{\mathrm{tg}} * \underline{\mathrm{P}_{\mathrm{g}}} \leq \mathrm{P}_{\mathrm{tsg}}^{\mathrm{ac}} \leq \mathrm{u}_{\mathrm{tg}} * \overline{\mathrm{P}_{\mathrm{g}}}
\end{aligned}
$$

Constraints (19) to (21) have been employed to model the minimum up time constraints in each scenario. The first relation stats that the thermal unit is not allowed to be shut down unless it has been running for sufficient period of time, represented byInitUp $\mathrm{g}_{\mathrm{g}}$. The second constraint guarantees that the thermal unit has been running for minimum up time from $t=I n i t U p_{g}+1$ to $\left(\mathrm{NT}-\mathrm{InitUp}_{\mathrm{g}}+1\right)$, for the rest of planning horizon. The last constraint apply the minimum-up time constraint to insure that any thermal unit started at any of these periods remains on until the end of the planning horizon.

$\sum_{\mathrm{t}=1}^{\mathrm{InitUpg}}\left(1-\mathrm{u}_{\mathrm{tg}}\right)=0, \forall \mathrm{g}$

$\sum_{n=t}^{t+I n i t U p_{g}-1} u_{n g} \geq \operatorname{MinUp}_{g} \cdot\left(u_{t g}-u_{t-1, g}\right)$

$\forall t=$ InitUp $_{g}+1 \ldots . . N T-$ MinUp $_{g}+1$

$\sum_{\mathrm{n}=\mathrm{t}}^{\mathrm{NT}} \mathrm{u}_{\mathrm{ng}}-\left(\mathrm{u}_{\mathrm{tg}}-\mathrm{u}_{\mathrm{t}-1, \mathrm{~g}}\right) \geq 0$

$\forall \mathrm{g}, \forall \mathrm{t}=\mathrm{NT}-\mathrm{MinUp}_{\mathrm{g}}+2 \ldots . \mathrm{NT}$.

Similarly, relations (22), (23) and (24) have been employed to enforce the minimum down time constraint.

$$
\begin{aligned}
& \sum_{\mathrm{t}=1}^{\mathrm{InitDn}_{\mathrm{g}}}\left(\mathrm{u}_{\mathrm{tg}}\right)=0, \forall \mathrm{g} \\
& \sum_{\mathrm{n}=\mathrm{t}}^{\mathrm{t}+\text { MinDng }_{\mathrm{g}}-1}\left(1-\mathrm{u}_{\mathrm{tg}}\right) \geq \operatorname{MinDn}_{\mathrm{g}}\left(\mathrm{u}_{\mathrm{t}-1, \mathrm{~g}}-\mathrm{u}_{\mathrm{t}, \mathrm{g}}\right)
\end{aligned}
$$


$\forall \mathrm{g}, \forall \mathrm{t}=\operatorname{InitDn}_{\mathrm{g}}+1 \ldots \mathrm{NT}-\mathrm{MinDn}_{\mathrm{g}}+1$

$\sum_{\mathrm{n}=\mathrm{t}}^{\mathrm{N}_{\mathrm{T}}}\left(1-\mathrm{u}_{\mathrm{ng}}\right)-\left(\mathrm{u}_{\mathrm{t}, \mathrm{g}}-\mathrm{u}_{\mathrm{t}-1, \mathrm{~g}}\right) \geq 0$

$\forall \mathrm{g}, \forall \mathrm{t}=\mathrm{N}_{\mathrm{T}}-\operatorname{MinDn}_{\mathrm{g}}+2 \ldots . \mathrm{N}_{\mathrm{T}}$

\section{Piecewise Linearization of the Thermal Cost Curve:}

As shown in (25), a quadratic function is used to express the thermal units generation cost [9], [26]. This nonlinear function is piece-wise linearized. In order to maintain the optimization problem as a linear program. This is done using (26) - (29).

$$
\begin{aligned}
& C_{g}\left(P_{t s g}^{a c}\right)=F C_{g} *\left(a+b * P_{t s g}^{a c}+c *\left(P_{t s g}^{a c}\right)^{2}\right) \\
& \mathrm{C}_{\mathrm{g}}\left(\mathrm{P}_{\mathrm{tsg}}^{\mathrm{ac}}\right)=\mathrm{FC}_{\mathrm{g}} *\left\{\mathrm{u}_{\mathrm{t}, \mathrm{g}} * \mathrm{AA}_{\mathrm{g}}+\sum_{\mathrm{e}=1}^{\mathrm{N}_{\mathrm{E}}} \text { Slope }_{\mathrm{etsg}}\right\}, \forall \mathrm{t}, \mathrm{s}, \mathrm{g} \\
& \mathrm{P}_{\mathrm{tsg}}^{\mathrm{ac}}=\underline{\mathrm{P}_{\mathrm{g}}} * \mathrm{u}_{\mathrm{tg}}+\sum_{\mathrm{e}=1}^{\mathrm{N}_{\mathrm{E}}} \delta_{\mathrm{etsg}}, \forall \mathrm{t}, \mathrm{s}, \mathrm{g} \\
& 0 \leq \delta_{\mathrm{etsg}} \leq \mathrm{BrkPt}_{\mathrm{eg}}-\mathrm{BrkPt}_{\mathrm{e}-1, \mathrm{~g}}, \forall \mathrm{e}, \mathrm{t}, \mathrm{s}, \mathrm{g} \\
& \mathrm{AA}_{\mathrm{g}}=\mathrm{a}+\mathrm{bP}_{\mathrm{g}}^{\mathrm{ac}}+\mathrm{c}\left(\underline{\mathrm{P}_{\mathrm{g}}^{\mathrm{ac}}}\right)^{2}, \forall \mathrm{g}
\end{aligned}
$$

\section{Non-decreasing Bidding Curves:}

Constraints (30)-(35) are employed to ensure non-decreasing bidding energy curves with respect to energy prices.

$$
\begin{aligned}
& \left(\rho_{\mathrm{ts}}-\rho_{\mathrm{ts̀}}\right)\left(\mathrm{PW}_{\mathrm{tsd}}-\mathrm{PW}_{\mathrm{ts̀d}}\right) \geq 0, \forall \mathrm{t}, \mathrm{s}, \grave{\mathrm{s}}, \mathrm{d} \\
& \text { if }\left(\rho_{\mathrm{ts}}-\rho_{\mathrm{ts}}\right)=0,\left(\mathrm{PW}_{\mathrm{tsd}}-\mathrm{PW}_{\mathrm{ts̀d}}\right)=0, \forall \mathrm{t}, \mathrm{s}, \grave{\mathrm{s}}, \mathrm{d} \\
& \left(\rho_{\mathrm{ts}}-\rho_{\mathrm{ts̀}}\right)\left(P p_{\mathrm{tsg}}-P p_{\mathrm{ts̀g}}\right) \geq 0, \forall \mathrm{t}, \mathrm{s}, \grave{s}, \mathrm{~g}
\end{aligned}
$$

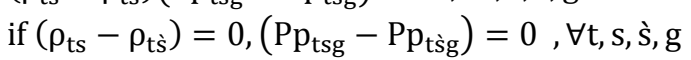

$$
\begin{aligned}
& \left(\rho_{\mathrm{ts}}-\rho_{\mathrm{ts̀}}\right)\left(\mathrm{PH}_{\mathrm{tsn}}-\mathrm{PH}_{\mathrm{tsh}}\right) \geq 0, \forall \mathrm{t}, \mathrm{s}, \grave{\mathrm{s}} \\
& \text { if }\left(\rho_{\mathrm{ts}}-\rho_{\mathrm{ts̀}}\right)=0,\left(\mathrm{PH}_{\mathrm{tsn}}-\mathrm{PH}_{\mathrm{tshn}}\right)=0, \forall \mathrm{t}, \mathrm{s}, \grave{\mathrm{s}}
\end{aligned}
$$

\section{Non-increasing Offers Curves:}

For the offers curves that should be submitted to the market, non-increasing offers constraints, as in (36) and (37) are used.

$\left(\rho_{\mathrm{ts}}-\rho_{\mathrm{ts̀}}\right)\left(\right.$ MarkPump $_{\mathrm{tsn}}-$ MarkPump $\left._{\mathrm{tsin}}\right) \leq 0, \forall \mathrm{t}, \mathrm{s}, \grave{\mathrm{s}}(36)$

if $\left(\rho_{\mathrm{ts}}-\rho_{\mathrm{ts̀}}\right)=0$, $\left(\right.$ MarkPump $_{\mathrm{tsn}}-$ MarkPump $\left._{\mathrm{tsin}}\right)=0, \forall \mathrm{t}, \mathrm{s}, \grave{\mathrm{s}}$

\section{Pumped-Storage System Constraints:}

The actual power generation and the bidding from each hydro unit operate in the generation mode in each hour and each scenario should be within its upper and lower capacity limits, as given by (38) and (39).

$0 \leq \mathrm{PH}_{\mathrm{tsn}} \leq \mathrm{G}_{\mathrm{tsn}} * \mathrm{PPSH}, \forall \mathrm{tsn}$

$0 \leq \mathrm{H}_{\mathrm{tsn}}^{\mathrm{ac}} \leq \mathrm{G}_{\mathrm{tsn}} * \mathrm{PPSH}, \forall \mathrm{tsn}$

Equation (40) express the total pumped energy through each hydro unit operates in the pumping mode in each hour in each scenario should be within its lower and upper limits. Relations (41), (42) and (43) shows that the pumped power from wind, thermal, or from the market, respectively, is limited by the online PSS pumping capacity. 
$0 \leq \mathrm{Pump}_{\text {tsn }} \leq \mathrm{P}_{\text {tsn }} * \mathrm{PPSH}$

$0 \leq \sum_{\mathrm{d}=1}^{\mathrm{N}_{\mathrm{d}}} \mathrm{W}_{\text {tsd }}^{\text {acp }} \leq \sum_{\mathrm{n}=1}^{\mathrm{N}_{\mathrm{U}}}\left(\mathrm{P}_{\mathrm{tsn}} * \mathrm{PPSH}\right)$

$0 \leq \sum_{\mathrm{g}=1}^{\mathrm{N}_{\mathrm{g}}} \mathrm{P}_{\mathrm{tsg}}^{\text {acp }} \leq \sum_{\mathrm{n}=1}^{\mathrm{N}_{\mathrm{U}}}\left(\mathrm{P}_{\mathrm{tsn}} * \mathrm{PPSH}\right)$

$0 \leq \mathrm{MP}_{\mathrm{ts}} \leq \sum_{\mathrm{n}=1}^{\mathrm{N}_{\mathrm{U}}}\left(\mathrm{P}_{\mathrm{tsn}} * \mathrm{PPSH}\right)$

$\mathrm{V}_{\mathrm{ts}}=\mathrm{V}_{\mathrm{t}-1, \mathrm{~s}}+\left\{\begin{array}{c}\mu_{\mathrm{P}} *\left(\sum_{\mathrm{n}=1}^{\mathrm{N}_{\mathrm{U}}} \text { Pump }_{\mathrm{tsn}}\right)- \\ \frac{1}{\mu_{\mathrm{G}}}\left(\sum_{\mathrm{N}=1}^{\mathrm{N}_{\mathrm{U}}} \mathrm{H}_{\mathrm{tsn}}^{\mathrm{ac}}\right)\end{array}\right\}$

$\underline{\mathrm{V}} \leq \mathrm{V}_{\mathrm{ts}} \leq \overline{\mathrm{V}}$

The energy level in the upper reservoir in each scenario in each hour of the day is described in equation (44); it's clearly shown the energy level in each time each hour depends on the previous energy level interval and the total pumped or generated energy via PSS facilities in the current interval taken into account the generation and pumping efficiencies. Note that, the energy level in all hours in each scenario should be within the minimum and maximum limits of the upper reservoir as in (45). But the initial energy and final energy levels in all scenarios are given by (46) and (47), respectively.

$\mathrm{V}_{\mathrm{ts}}=\mathrm{V}^{\text {Initial }}, \mathrm{t}=0, \forall \mathrm{s}$

$\mathrm{V}_{\mathrm{ts}}=\mathrm{V}^{\text {Final }}, \mathrm{t}=24, \forall \mathrm{s}$

Equation (48) shows the total pumped energy to the upper reservoir. It is a combination from the actual thermal and wind generation in addition to the purchased energy from the market in each hour in each scenario.

$\sum_{\mathrm{n}=1}^{\mathrm{N}_{\mathrm{U}}}$ Pump $_{\mathrm{tsn}}=$ MarkPump $_{\mathrm{ts}}+\mathrm{W}_{\mathrm{ts}}^{\mathrm{acp}}+\sum_{\mathrm{g}=1}^{\mathrm{N}_{\mathrm{G}}} \mathrm{P}_{\mathrm{psg}}^{\mathrm{acp}}, \forall \mathrm{ts}$

Each hydro unit in PSS can operate in one of three modes; pumping mode, generation mode, or offline mode. Offline means the hydro unit is not operated in either the first two modes. To achieve this purpose constraint (49) is employed. $\mathrm{G}$ and $\mathrm{P}$ are integer decision variables which represent the hydro unit operating mode, i.e. generation or pumping modes. Constraints in (50) and (51) are employed to insure each hydro unit should stay in the offline mode at least for one hour when it's needed to change the mode from the generation mode to the pumping mode or the opposite [10, 27]. All of the hydro units in all scenarios in PSS are assumed to be initially in the offline mode which is clearly shown in (52) and (53).

$P_{t s n}+G_{t s n} \leq 1$
$P_{t-1 s n}+G_{t s n} \leq 1$
$P_{t s n}+G_{t-1 s n} \leq 1$
$G_{0 s n}=0$,
$P_{0 s n}=0$,

\section{SYSTEM DESCRIPTION}

The test system consists of one wind farm, five thermal units and one pumped storage power plant. The total installed capacity is $660 \mathrm{MW}$; 430MW thermal, 200MW wind. The maximum upper reservoir capacity for PSS is 600MWh. PSS consists of four hydro units, 30MW each. These units can operate either as a hydro generator or as a pump.

The technical characteristics for the thermal units and the hydro units are presented in appendix. Note that the PSS hydro units are assumed to have high flexibility; each unit can ramp from 0 MW to its full capacity in one hour. The day ahead wind power output scenarios are taken from [9] as well as the day ahead energy market and imbalances prices scenarios. 
In this problem there are three uncertain parameters; day ahead wind outputs, day ahead energy market prices and up/down imbalance prices. Five scenarios are used for each of these parameters. That is, the scenario tree contains $5 \times 5 \times 5=125$ Scenarios.

For risk, a commonly used value of the confidence level of $\alpha=0.95$ is used to calculate CVaR [9, 21].

\section{RESULTS AND DISCUSSIONS}

Several tests have been done on the proposed system algorithm to come out with comparable results from the coordinated Wind-Thermal-PSS generation, and a coordinated Wind-Thermal generation uncoordinated with PSS, the results mainly are the bidding and offering strategies with several risk-aversion levels. The obtained results are also involving the next 24 hours self-schedule unit commitment for the thermal units and pumped storage power plant. The additional profits and CVaR resulted by installing PSS are also discussed.

A.Unit commitment and PSS states schedules

TABLE I HYDRO UNITS STATE SCHEDULE FOR COORDINATED AND UNCOORDINATED PSS, $\beta=0$

\begin{tabular}{|l|l|l|l|l|l|l|l|l|l|l|l|l|}
\hline Beta $=$ 0 & h1 & h2 & h3 & h4 & h5 & h6 & h7 & h8 & h9 & h10 & h11 & h12 \\
\hline Unit Number & 1234 & 1234 & 1234 & 1234 & 1234 & 1234 & 1234 & 1234 & 1234 & 1234 & 1234 & 1234 \\
\hline P & 0000 & 1000 & 1111 & 1111 & 1111 & 1111 & 1011 & 0000 & 0000 & 0000 & 0000 & 0000 \\
G & 0111 & 0000 & 0000 & 0000 & 0000 & 0000 & 0000 & 0100 & 1111 & 1111 & 1111 & 1111 \\
\hline P un & 0000 & 0000 & 1111 & 1111 & 1111 & 1111 & 0000 & 0000 & 0000 & 0000 & 0000 & 0000 \\
G un & 1111 & 0000 & 0000 & 0000 & 0000 & 0000 & 0000 & 0000 & 0000 & 1111 & 1111 & 1111 \\
\hline & h13 & h14 & h15 & h16 & h17 & h18 & h19 & h20 & h21 & h22 & h23 & h24 \\
\hline Unit Number & 1234 & 1234 & 1234 & 1234 & 1234 & 1234 & 1234 & 1234 & 1234 & 1234 & 1234 & 1234 \\
\hline P & 0000 & 0000 & 0000 & 1000 & 1100 & 0000 & 0000 & 0000 & 0000 & 0000 & 0000 & 0111 \\
\hline G & 1111 & 1111 & 0111 & 0011 & 0011 & 0011 & 0011 & 1111 & 1111 & 1111 & 0000 & 1000 \\
\hline P un & 0000 & 0000 & 0000 & 0000 & 0000 & 0000 & 0000 & 0000 & 0000 & 0000 & 0000 & 1000 \\
\hline G un & 1111 & 1111 & 0000 & 0000 & 0000 & 0000 & 0000 & 1111 & 1111 & 1111 & 0000 & 0000 \\
\hline
\end{tabular}

Table I provides the hydro unit commitment state schedule for the PSS units. The hydro unit can be in one of three states pumping, generation, or off-line; P and G represent either the unit in the pumping mode or in the generation mode, respectively in the coordinated PSS. Pun and Gun represent the hydro unit state in the uncoordinated PSS. PSS is utilized more often in the coordinated case over the uncoordinated one by 1.5 times. This is because it is not only the purchased energy from the market is used to be stored in the upper reservoir, but also a portion of the actual wind and thermal generation could be stored in the scenarios that have slightly low energy price take into account the lowest imbalance up prices scenarios. Moreover, this allow the PSS to operate more often in the generation mode that's mean PSS can supply the mismatch between the actual and the bidding in wind and thermal energy in the scenarios that have slightly high imbalance down and energy prices.

Tables II shows the thermal unit commitment schedule for coordinated and uncoordinated PSS at risk-neutral case. In this case, the coordination did not change the commitment schedule of any of thermal units. 


\begin{tabular}{|c|c|} 
Unit 2 & 000000001111110000011100 \\
\cline { 1 - 1 } Unit 3 & 000000011111111111111110 \\
\cline { 1 - 1 } Unit 4 & 110000011111111111111110 \\
\cline { 1 - 1 } Unit 5 & 110000111111111111111111 \\
\hline
\end{tabular}

Tables III is showing the thermal unit commitment schedule for $\beta=0.5$ in both coordinated and uncoordinated PSS, where the bolded digits in Table III are showing the difference in the thermal unit commitment schedule from riskneutral case and the risk-aversion at level $\beta=0.5$. To avoid the risky scenarios at risk-neutral case as in table II the thermal units needs to be committed more often than the case of $\beta=0.5$.

TABLE III THERMAL UNIT COMMITMENT SCHEDULE FOR COORDINATED PSS, $\beta=0.5$
\begin{tabular}{|l|l|}
\hline$\beta=0.5$ & Hours(1-24) \\
\hline Unit 1 & 100000011111111111111111 \\
\hline Unit 2 & 000000000000000000000000 \\
\hline Unit 3 & 000000001111110000011100 \\
\hline Unit 4 & 1100000111111111111111110 \\
\hline Unit 5 & 110000111111111111111111 \\
\hline
\end{tabular}

\section{B. Energy bids and offers}

Figures 1, 2, and 3 shows the offered energy to be purchased from energy market to energize the hydro units in hours 3, 5, and 6, respectively. Most of the time, the offered energy in the uncoordinated PSS is much higher than it in the coordinated one; the system use a portion of the wind and thermal power output to decrease the purchased energy.

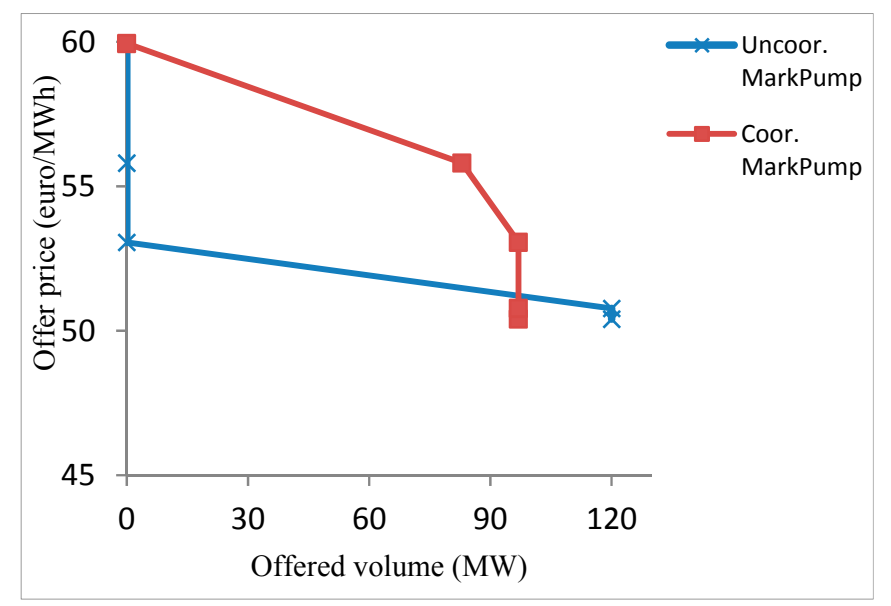

Fig1. Offered energy curve for hour $3, \beta=0$.

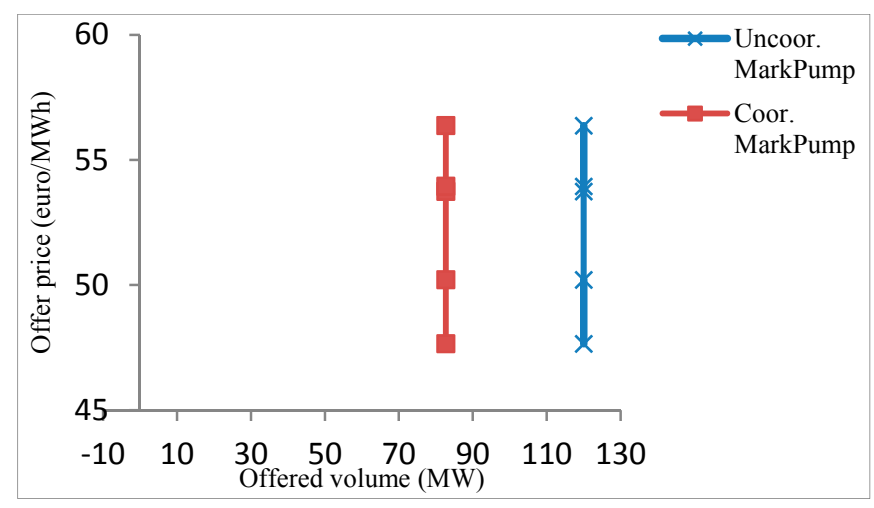


Fig2. Offered energy curve for hour $5, \beta=0$.

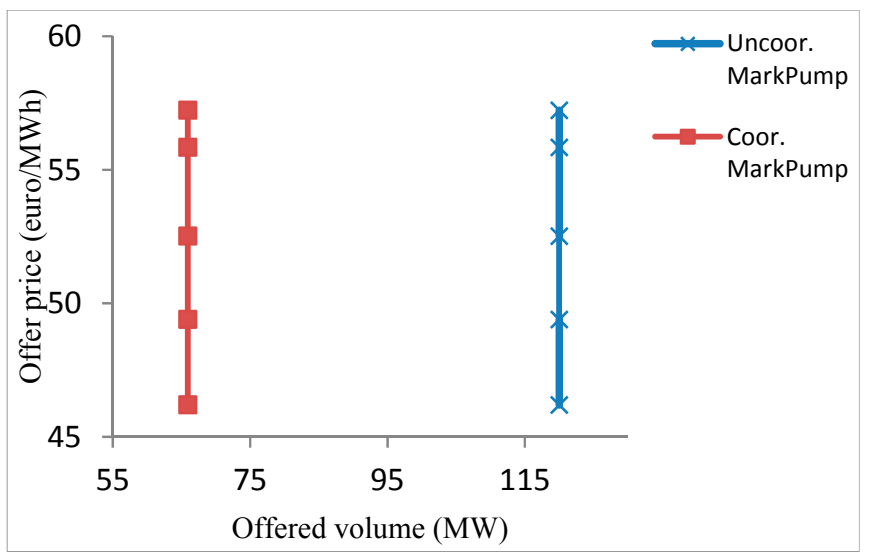

Fig3. Offered energy curve for hour $6, \beta=0$.

Figure 4 depicts the expected value of the pumped energy in the coordinated PSS at Risk-neutral level. Clearly in the low energy price periods (from hour 3 to hour6), the expected value of the pumped energy from the market is much higher than others. However the other pumping mode periods (hour 2, 7, and 24) the expectation value of the pumped energy from the market goes to zero, where the expectation values of the pumped energy from the actual wind and thermal generation remain above zero, therewith the expectation value of the pumped energy from the actual wind power always much higher than the expected value of the pumped energy from thermal generation.

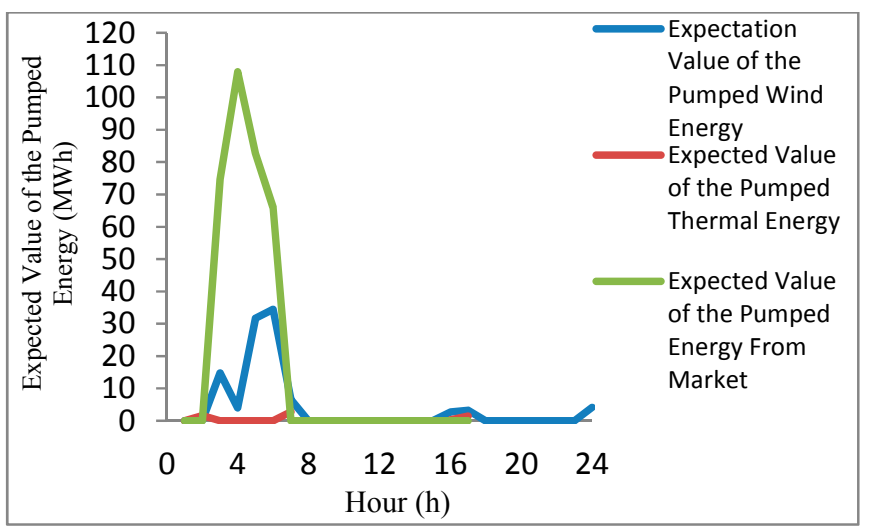

Fig4. Expected Values of the Pumped Energy, $\beta=0$.

Figures 5 to 7 show the bidding curves for hours 1,9,11 and 20 respectively at Risk neutral case for coordinated and uncoordinated PSS. In all hour's coordinated and uncoordinated thermal biddings are different with same unit commitment schedule, also in hours 11 and 21 the coordination PSS make a big difference in PSS bidding curves. 


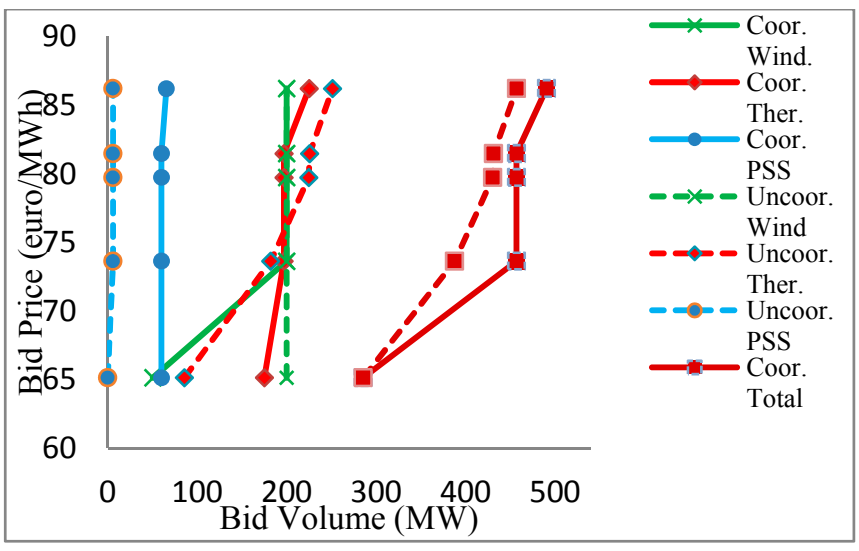

Fig5. Bidding curves for hour11, $\beta=0$.

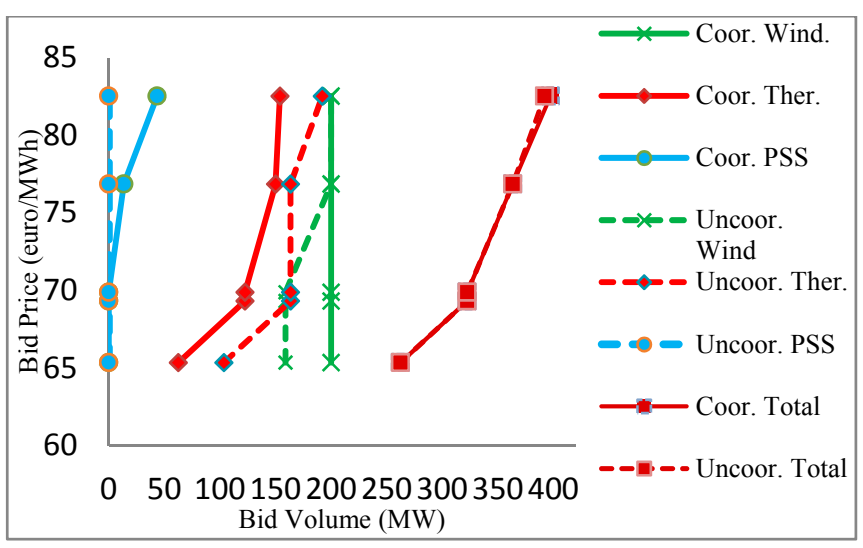

Fig6. Bidding curves for hour19, $\beta=0$.

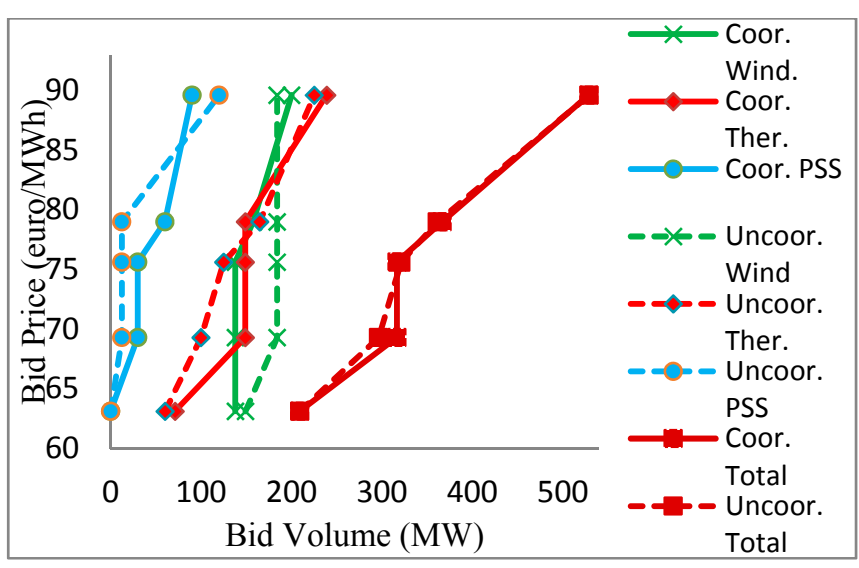

Fig7. Bidding curves for hour20, $\beta=0$.

Figures 8 to 10 provide the bidding curves at risk-averse for coordinated and uncoordinated PSS in hours 11, 19, and 20 respectively when PSS work in generation mood. It's worthy to mention that the coordination change the bidding curves for thermal and PSS. 


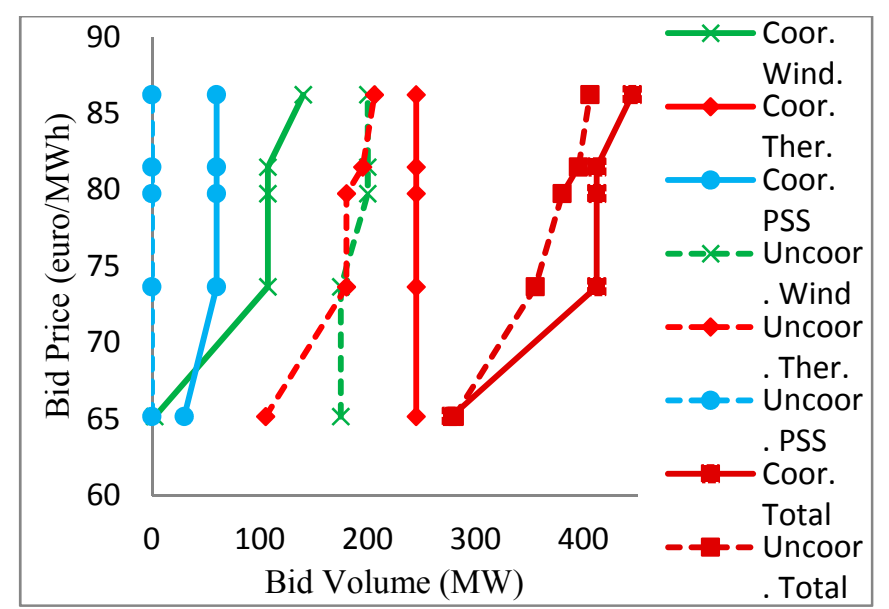

Fig8. Bidding curves for hour11, $\beta=0.5$.

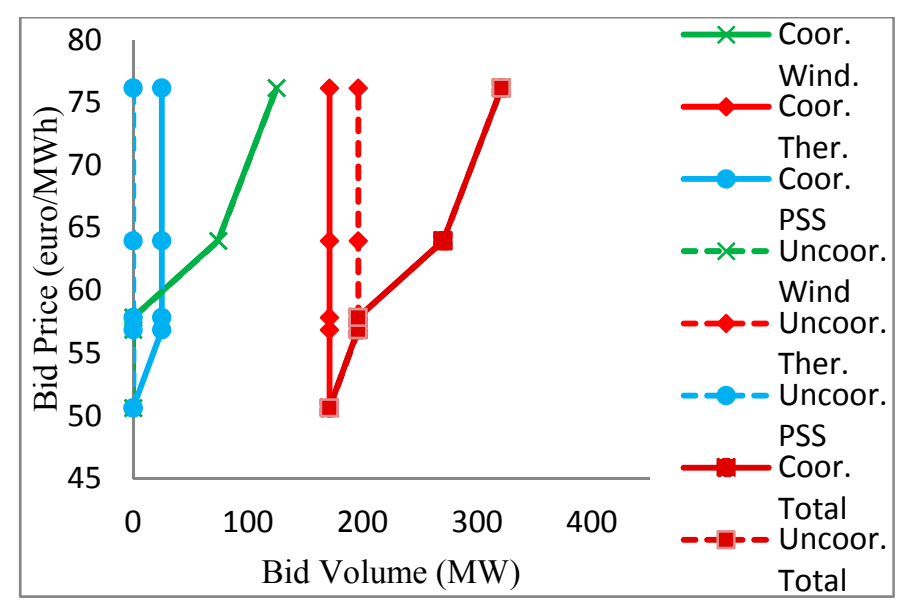

Fig9. Bidding curves for hour19, $\beta=0.5$.

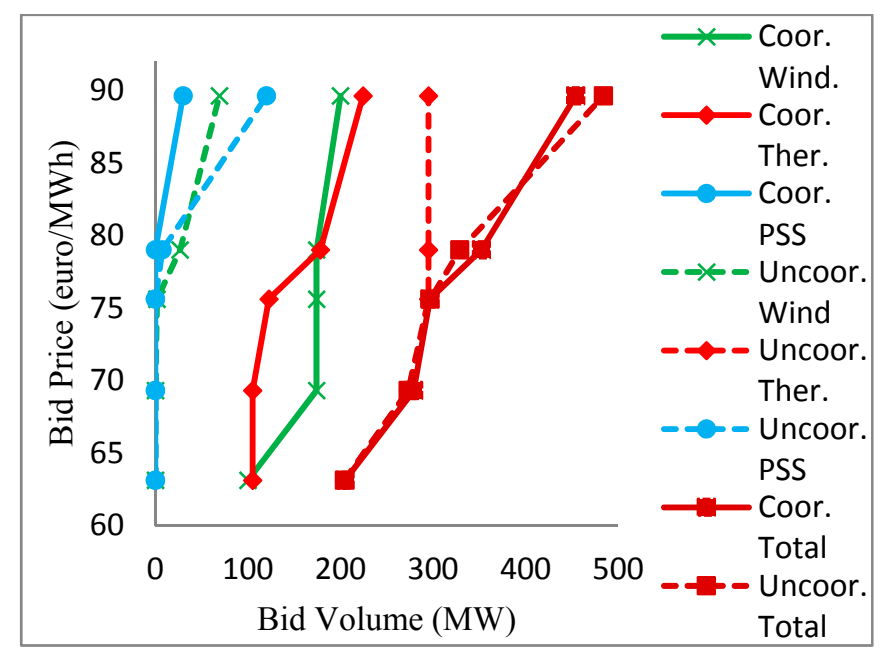

Fig10. Bidding curves for hour20, $\beta=0.5$.

Figure 11 shows the difference total bidding curves at risk-neutral and risk-averse $(\beta=0.5)$, the result shows the total bidding in risk neutral curves are more or equal the total bids in risk-averse curves. PSS and thermal units tend to be committed more often at risk neutral case. 


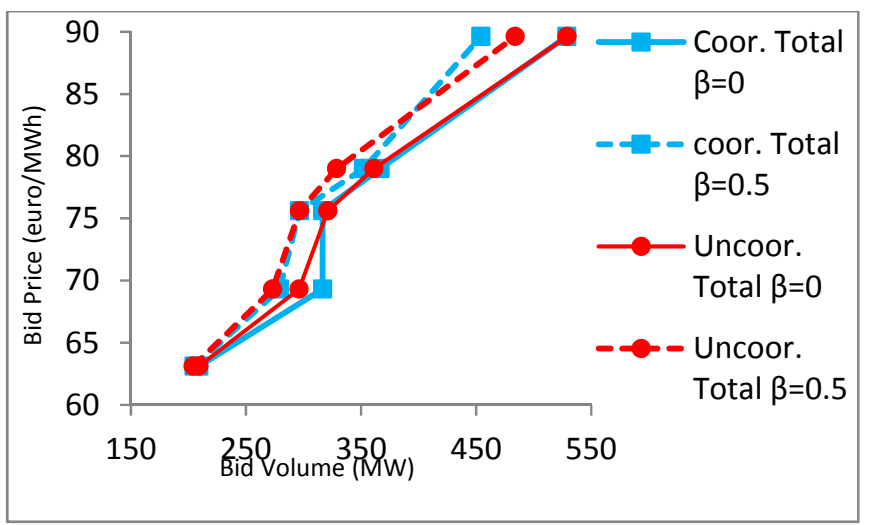

Fig11. Total bidding curves for coordinated and uncoordinated PSS for hour20, $\beta=0 \& \beta=0.5$.

Figures 12 and 13 show the bidding curves for hours 5 and 6 respectively at risk-neutral optimization. Where figures 14 and 15 show the bidding curves for the same hours at risk-aversion optimization $\beta=0.5$. Obviously, the coordination reduces PSS and total bidding volumes to purchase energy from the market in both risk-neutral and risk-aversion optimization.

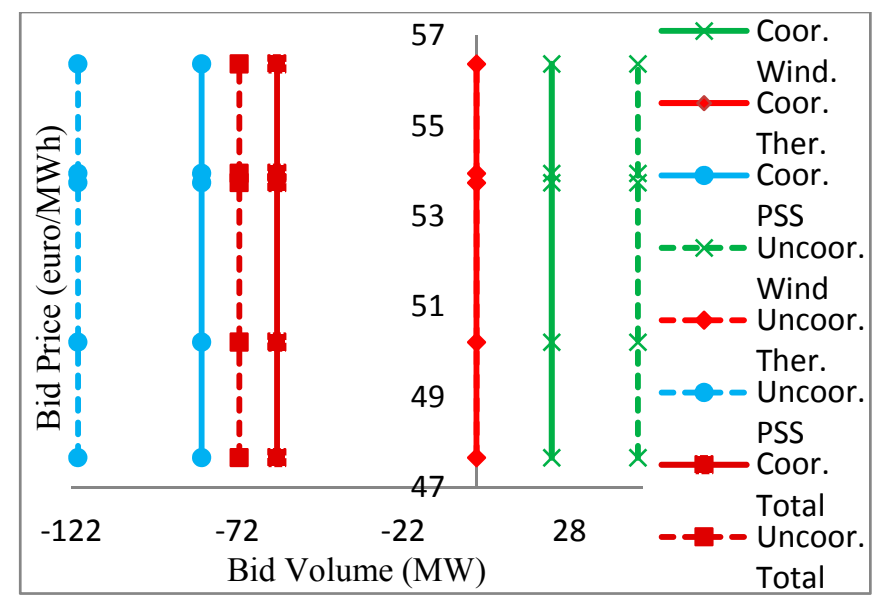

Fig12. Total bidding curves for coordinated and uncoordinated PSS for hour $5, \beta=0$.

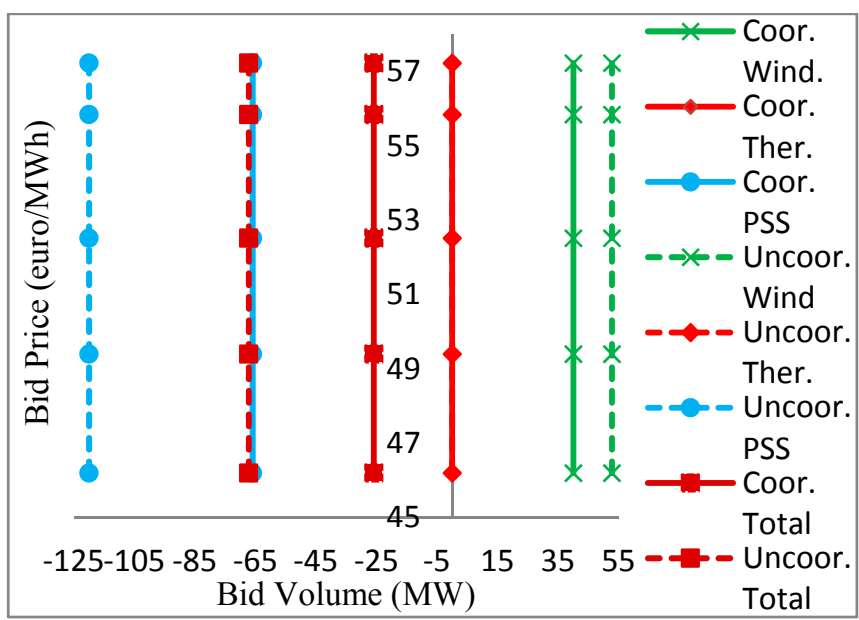

Fig13. Total bidding curves for coordinated and uncoordinated PSS for hour $6, \beta=0$. 


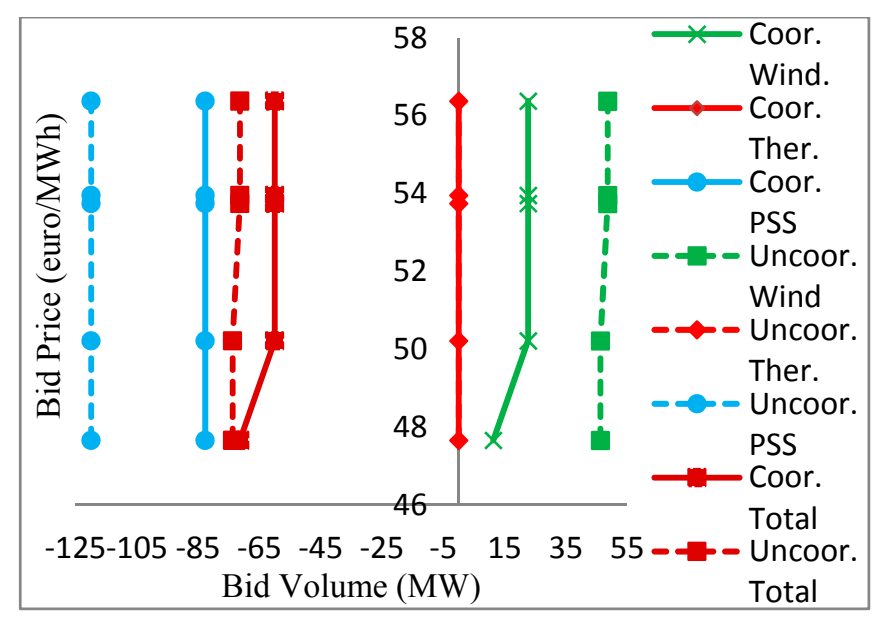

Fig14. Total bidding curves for coordinated and uncoordinated PSS for hour $5, \beta=0.5$.

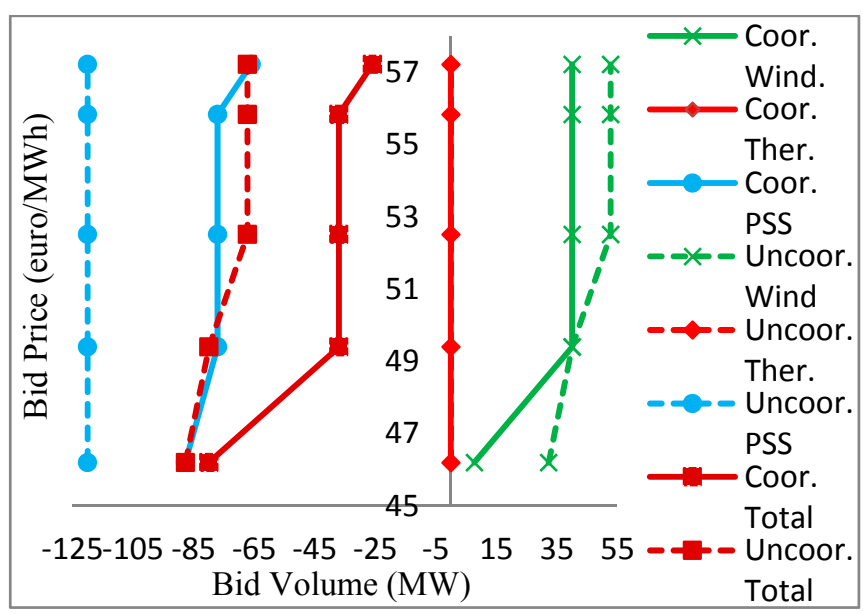

Fig15. Total bidding curves for coordinated and uncoordinated PSS for hour $6, \beta=0.5$.

\section{Risk analysis and profit gains}

Figures 16 and 17 shows the relationship between the expected profit and CVaR in different risk-aversion for the coordinated and uncoordinated PSS respectively, as expected results CVaR increases and the profit decreases with the increasing of $\beta$.

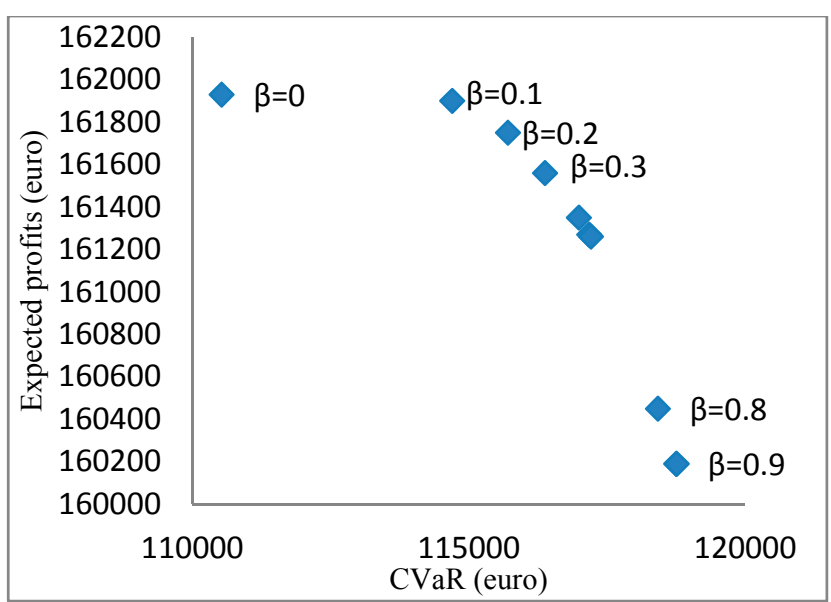

Fig16. Expected profits and CVaR for uncoordinated wind-thermal bidding 


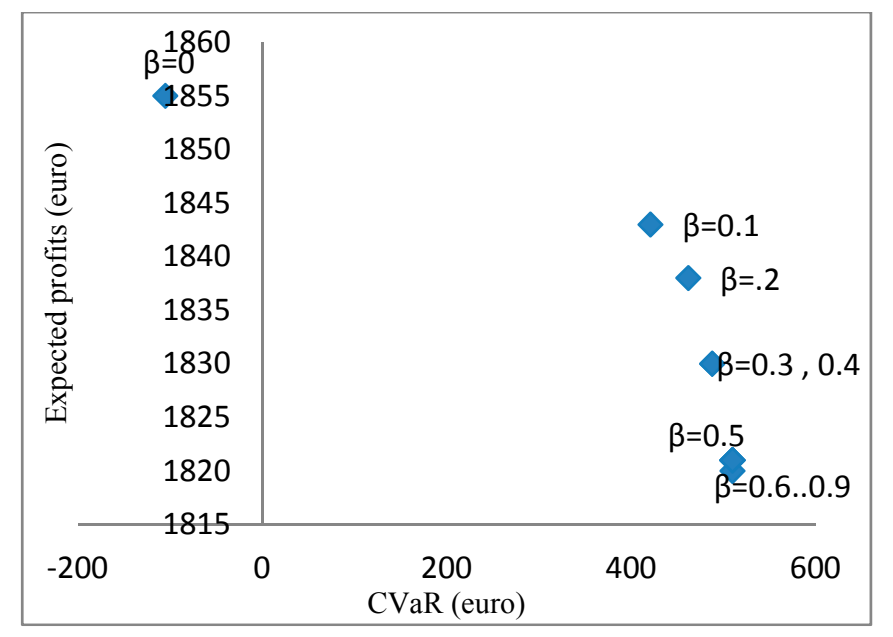

Fig12. Expected profits and CVaR for uncoordinated PSS bidding

It's worthy to mention that when $\beta$ increased from 0 to 0.1 the expected profit decreased by $0.0356 \%$ in and CVaR increased by $4.2527 \%$ in the uncoordinated bidding; however the same change in $\beta \mathrm{CVaR}$ increase by 3.763 with profits decreasing by $0.0356 \%$, but still the expected profits and CVaR is much more in the coordinated PSS over than the uncoordinated one and it's clearly shown in figure 13.

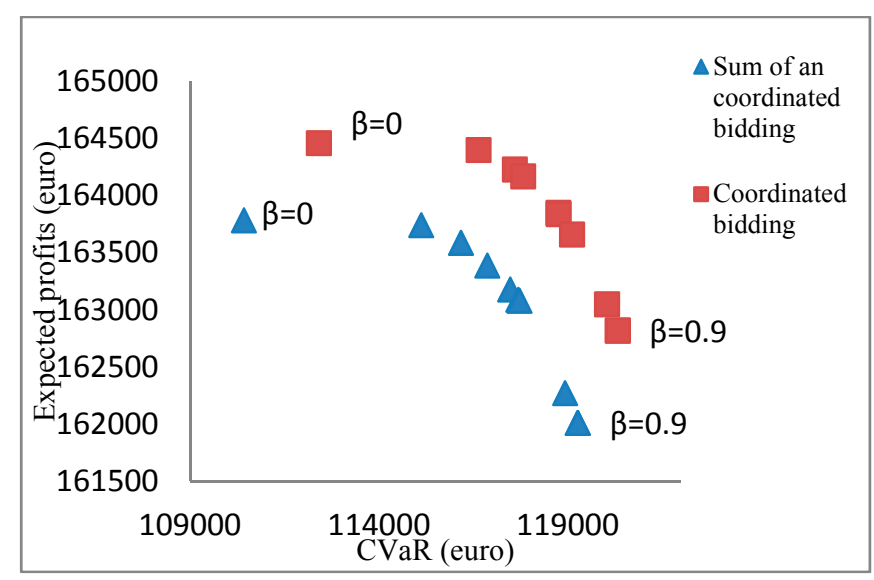

Fig17. Expected profits and CVaR for coordinated uncoordinated bidding

At risk-neutral case percentage profit gain from the coordination of PSS over the uncoordinated one is $0.412 \%$ and the $\mathrm{CVaR}$ gain is $1.798 \%$, it's clearly observed from figure 13 and table I these gains remain positives and around these values as $\beta$ increased.

\section{CONCLUSION}

In this work a mixed integer stochastic programming have been solved to obtain the optimal bidding strategy for a generation company owns wind-thermal generation integrated with PSS, the additional values by coordinate PSS with the existent wind-thermal units have been obtained. PSS is a good solution to demolish the uncertainty in the system which caused by owning uncertain generation resources such wind turbine. PSS make a significant difference in risk level as well as in the total profits. The mathematical formulation that used in this work is valid and suitable to be used by generation companies to participate in a pool based day-ahead energy market. 


\section{APPENDEX}

The thermal units and PSS characteristics data that used in this paper are given in tables IV and V respectively.

TABLE IV

THERMAL UNITS' DATA

\begin{tabular}{|c|c|c|c|c|c|c|c|c|c|c|c|}
\hline unit & $\begin{array}{c}\text { Pmin } \\
(\mathrm{MW})\end{array}$ & $\begin{array}{c}\text { Pmax } \\
(\mathrm{MW})\end{array}$ & $\begin{array}{c}\text { MinUP } \\
(\mathrm{Hrs})\end{array}$ & $\begin{array}{c}\text { MinDn } \\
(\mathrm{Hrs})\end{array}$ & $\begin{array}{c}\text { RU } \\
(\mathrm{MW} / \mathrm{Hr})\end{array}$ & $\begin{array}{c}\text { RD } \\
(\mathrm{MW} / \mathrm{Hr})\end{array}$ & $\begin{array}{c}\text { Uic } \\
(\mathrm{Hrs})\end{array}$ & $\begin{array}{c}\text { StUpCost } \\
(€)\end{array}$ & $\begin{array}{c}\mathrm{a} \\
(\mathrm{Mbtu} / \mathrm{h})\end{array}$ & $\begin{array}{c}\mathrm{b} \\
(\mathrm{Mbtu} / \mathrm{h})\end{array}$ & $\begin{array}{c}\mathrm{c} \\
(\mathrm{Mbtu} / \mathrm{h})\end{array}$ \\
\hline 1 & 0.01 & 50 & 1 & 1 & 50 & 50 & 0 & 0 & 0 & 80 & 0 \\
\hline 2 & 5 & 45 & 1 & 1 & 15 & 15 & 0 & 88 & 85.51 & 70.86 & 0.188 \\
\hline 3 & 5 & 45 & 1 & 1 & 15 & 15 & 0 & 88 & 82.34 & 68.23 & 0.181 \\
\hline 4 & 25 & 100 & 5 & 5 & 50 & 50 & 0 & 110 & 32.99 & 64.42 & 0.042 \\
\hline 5 & 25 & 100 & 5 & 5 & 50 & 50 & 0 & 110 & 32.99 & 57.92 & 0.042 \\
\hline
\end{tabular}

TABLE V

PSS UNITS' DATA

\begin{tabular}{|c|c|c|c|c|c|c|c|c|c|c|}
\hline unit & $\begin{array}{l}\text { Pmin } \\
(\mathrm{MW})\end{array}$ & $\begin{array}{c}P \max \\
(\mathrm{MW})\end{array}$ & $\begin{array}{l}\text { MinUP } \\
\text { (Hrs) }\end{array}$ & $\begin{array}{l}\text { MinDn } \\
\text { (Hrs) }\end{array}$ & $\begin{array}{c}\text { RU } \\
(\mathrm{MW} / \mathrm{Hr})\end{array}$ & $\begin{array}{c}\mathrm{RD} \\
(\mathrm{MW} / \mathrm{Hr})\end{array}$ & $\begin{array}{l}\text { StUpCost } \\
(€)\end{array}$ & $\begin{array}{c}\mathrm{CHO} \\
(€ / \mathrm{MWh})\end{array}$ & $\begin{array}{l}\text { Pumping } \\
\text { efficiency }\end{array}$ & $\begin{array}{c}\text { Generation } \\
\text { efficiency }\end{array}$ \\
\hline All & 0 & 30 & 0 & 0 & 30 & 30 & 0 & 3 & 0.85 & 0.9 \\
\hline
\end{tabular}

\section{REFERENCES}

[1] G. Akhtar and A. T. Al-Awami, "Emission-aware energy trading by coordinating thermal \& wind power generation," in Power Engineering, Energy and Electrical Drives (POWERENG), 2013 Fourth International Conference on, 2013, pp. 1023-1027.

[2] C. Flavin and M. H. Aeck, "ENERGY FOR DEVELOPMENT."

[3] J. P. Barton and D. G. Infield, "Energy storage and its use with intermittent renewable energy," Energy Conversion, IEEE Transactions on, vol. 19, pp. 441-448, 2004.

[4] W. Leonhard and E. M. Grobe, "Sustainable electrical energy supply with wind and pumped storage-a realistic long-term strategy or utopia?," in Power Engineering Society General Meeting, 2004. IEEE, 2004, pp. 1221-1225.

[5] J. Garcia-Gonzalez, R. R. de la Muela, L. M. Santos, and A. M. González, "Stochastic joint optimization of wind generation and pumpedstorage units in an electricity market," Power Systems, IEEE Transactions on, vol. 23, pp. 460-468, 2008.

[6] K. Rohrig and B. Lange, "Improving security of power system operation applying DG production forecasting tools," in Power and Energy Society General Meeting-Conversion and Delivery of Electrical Energy in the 21st Century, 2008 IEEE, 2008, pp. 1-6.

[7] M. Khatibi and M. Jazaeri, "An analysis for increasing the penetration of renewable energies by optimal sizing of pumped-storage power plants," in Electric Power Conference, 2008. EPEC 2008. IEEE Canada, 2008, pp. 1-5.

[8] B. Ummels, E. Pelgrum, and W. Kling, "Integration of large-scale wind power and use of energy storage in the Netherlands' electricity supply," Renewable Power Generation, IET, vol. 2, pp. 34-46, 2008.

[9] A. T. Al-Awami and M. A. El-Sharkawi, "Coordinated trading of wind and thermal energy," Sustainable Energy, IEEE Transactions on, vol. 2, pp. 277-287, 2011.

[10] S. J. Kazempour, M. Hosseinpour, and M. P. Moghaddam, "Self-scheduling of a joint hydro and pumped-storage plants in energy, spinning reserve and regulation markets," in Power E Energy Society General Meeting, 2009. PES'09. IEEE, 2009, pp. 1-8.

[11] C. Corchero and F. Heredia, "Optimal Day-Ahead bidding in the MIBEL's multimarket energy production system," in Energy Market (EEM), 2010 7th International Conference on the European, 2010, pp. 1-6. 
[12] http://en.wikipedia.org/wiki/Pumped-storage hydroelectricity.

[13] P. D. Brown, J. Peas Lopes, and M. A. Matos, "Optimization of pumped storage capacity in an isolated power system with large renewable penetration," Power Systems, IEEE Transactions on, vol. 23, pp. 523-531, 2008.

[14] G. Chen, D. Liu, F. Wang, and C. Ou, "Determination of installed capacity of pumped storage station in WSP hybrid power supply system," in Sustainable Power Generation and Supply, 2009. SUPERGEN'09. International Conference on, 2009, pp. 1-5.

[15] S. Papaefthimiou, E. Karamanou, S. Papathanassiou, and M. Papadopoulos, "Operating policies for wind-pumped storage hybrid power stations in island grids," Renewable Power Generation, IET, vol. 3, pp. 293-307, 2009.

[16] R. Jiang, J. Wang, and Y. Guan, "Robust unit commitment with wind power and pumped storage hydro," Power Systems, IEEE Transactions on, vol. 27, pp. 800-810, 2012.

[17] C. Xingying, W. Hexian, and Z. Xiaohua, "Studies on the Unit Commitment of Thermal-Pumped Storage Plant Considering the Rapid Adjustment Characteristic of Pumped Storage Plant," in Computer Distributed Control and Intelligent Environmental Monitoring (CDCIEM), 2011 International Conference on, 2011, pp. 1314-1318.

[18] J.-c. CUI, D.-h. LIU, W.-l. LIANG, F. XIE, and H.-y. CHEN, "Analysis on economic and environmental benefit of pumped-storage station [J]," Electric Power, vol. 1, p. 002, 2007.

[19] C. Wang, X. Niu, F. Li, X. Li, M. Lei, L. Fu, and R. Ni, "Consideration of pumped storage as a black-start source in Shandong power grid of China," in Innovative Smart Grid Technologies-Asia (ISGT Asia), 2012 IEEE, 2012, pp. 1-5.

[20] W. Li, J. Huang, G. Li, and Z. Wang, "Research on optimizing operation of the single reservoir of hybrid pumped storage power station," in Electric Utility Deregulation and Restructuring and Power Technologies (DRPT), 2011 4th International Conference on, 2011, pp. 1389-1394.

[21] J. M. Morales, A. J. Conejo, and J. Pérez-Ruiz, "Short-term trading for a wind power producer," Power Systems, IEEE Transactions on, vol. 25, pp. 554-564, 2010.

[23] H. Heitsch and W. Römisch, "Scenario reduction algorithms in stochastic programming," Computational optimization and applications, vol. 24, pp. 187-206, 2003.

[24] W. F. Sharpe and G. M. Cooper, "Risk-return classes of New York stock exchange common stocks, 1931-1967," Financial Analysts Journal, pp. 46-81, 1972.

[25] R. T. Rockafellar and S. Uryasev, "Optimization of conditional value-at-risk," Journal of risk, vol. 2, pp. 21-42, 2000.

[26] A. J. Wood and B. F. Wollenberg, Power generation, operation, and control: John Wiley \& Sons, 2012.

[27] S. Jalal Kazempour, A. Yousefi, K. Zare, M. P. Moghaddam, M. Haghifam, and G. Yousefi, "A MIP-based optimal operation scheduling of pumped-storage plant in the energy and regulation markets," in Universities Power Engineering Conference, 2008. UPEC 2008. 43rd International, 2008, pp. 1-5.

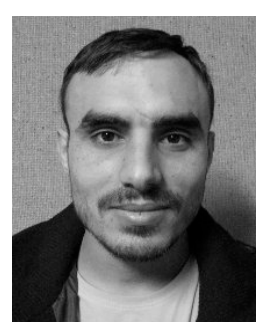

Mustafa S. AL-Swaiti Graduated from Palestine Technical University-Kadoorie with honor, and he is currently pursuing his MSC at King Fahd University for Petroleum and Minerals KFUPM. His employment experience included Southern electricity company (SELCO) as an electrical engineer. $\mathrm{He}$ is currently working as research assistant at KFUPM. His research interest includes power system operation, power system analysis, micro-grid, and renewable energy.

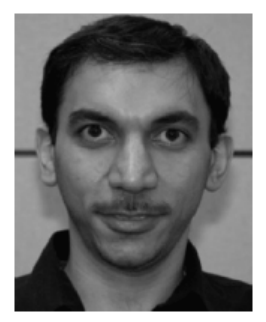

Ali T. Al-Awami (M'01) received the B.Sc. and M.Sc. degrees in electrical engineering from King Fahd University of Petroleum \& Minerals (KFUPM), Dhahran, Saudi Arabia, in 2000 and 2005, respectively, and the Ph.D. degree from the University of Washington, Seattle, in 2010. In 2000 he joined the Saudi Electricity Company as a System Operation Engineer. In 2002, he joined KFUPM as a Graduate Assistant, where he is currently an Assistant Professor there. He authored and coauthored several papers and book chapters in his research areas. His research interests include power system operation and optimization and the integration of renewable energy sources into the smart grid. 